\title{
MESO AND RACEMIC 1,1-BIS (BENZYLSULFINYL)-2-ETHYLBUTANE. A b-DISULFOXIDE PRO-LIGAND WITH STERIC RESTRICTIONS
}

\author{
M. ZÁRRAGA O. ${ }^{*}{ }^{1}$ Y. MORENO N., ${ }^{2}$ C. FRANCO O. ${ }^{3}$ \\ 'Department of Organic Chemistry, Faculty of Chemical Sciences, University of Concepción, 160-C, Concepción, Chile. \\ ${ }^{2}$ Dpto. Cs. Químicas, Fac. Cs. Exactas, Universidad Andrés Bello, Viña del Mar, Chile. \\ ${ }^{3}$ Faculty of Sciences, Department of Environment Chemistry, Catholic University of Sssa. Conception, Chile.
}

\begin{abstract}
Coordination chemistry of disulfoxides is of interest in inorganic chemistry given the well-known metal coordination through oxygen or sulfur atoms. ${ }^{1}$ Ethylene and propylene bridged disulfoxide pro-ligands, coordinate to metals, forming coordinated and chelated complexes, demonstrating its flexibility in the formation of such complexes. ${ }^{2}$ Some of these compounds have demonstrated interesting properties in medicinal chemistry ${ }^{3}$ and asymmetric catalysis ${ }^{4}$ and their synthesis is of importance for bioorganic studies. The presence of two stereogenic centers allows the existence of the meso and racemic forms in disulfoxides. Previous studies on b-disulfoxides 5 in our laboratories have led to the synthesis and spectroscopic study ( $\left.{ }^{1} \mathrm{H}-\mathrm{NMR}, \mathrm{FT}-\mathrm{IR}\right)$ of both diastereomeric forms. In this work we report the synthesis and structural analysis of meso-(2)- and racemic-(3)-1,1-bis(benzylsulfinyl)-2-ethylbutane (Scheme1), with high steric requirement around both sulfinyl groups when a branched aliphatic carbon chain is introduced in the a-carbon. An increase in selectivity for small radius metal ions was achieved by compression of the pro-ligand coordination radius. These kind of compounds have not been previously studied.
\end{abstract}

\section{EXPERIMENTAL}

${ }^{1} \mathrm{H}$ and ${ }^{13} \mathrm{C}$ NMR spectra were recorded on a Bruker AC 250 spectrometer ( $250 \mathrm{MHz}$ for ${ }^{1} \mathrm{H}$ and $62.4 \mathrm{MHz}$ for ${ }^{13} \mathrm{C}$ ) in $\mathrm{CDCl}_{3}$ and TMS as internal standard. Chemical shifts are expressed in delta units (ppm) and coupling constants in Hertz (Hz). FT-IR spectra were recorded on a Nicolet 550 IR spectrometer.

\section{1,1-bis(benzyl)-2-ethylbutyl dithioacetal (1)}

To a mixture of $25 \mathrm{~g}(0.25 \mathrm{~mol})$ of 2-ethylbutanal, $1 \mathrm{~mL}$ of $\mathrm{HCl}$ (c) and $200 \mathrm{mg}$ of $\mathrm{AlCl}_{3}$, was slowly added $0,55 \mathrm{~mol}$ of benzylthiol. The mixture was kept at room temperature and stirred for $6 \mathrm{~h}$. After that, water $(20 \mathrm{~mL})$ and $\mathrm{CH}_{2} \mathrm{Cl}_{2}(3 \times 20 \mathrm{~mL})$ was added to extract the product. The organic phase was treated with $\mathrm{NaOH} 3.0 \mathrm{M}(2 \times 20 \mathrm{~mL})$ and dried over anhydrous sodium sulfate. Removal of the solvent and vacuum distillation $\left(99-102^{\circ} \mathrm{C} / 0.1 \mathrm{mmHg}\right)$ gave (1), $70.1 \mathrm{~g}, 85 \%$ yield. Anal. Found (calcd.): S 19.4(19.4). ${ }^{1} \mathrm{H}-\mathrm{NMR}$ (d ppm) 7.35-7.20 (10 H, m), $3.68(4 \mathrm{H}, \mathrm{s}), 3.58(1 \mathrm{H}, \mathrm{d}, \mathrm{J}=5.0 \mathrm{~Hz}), 1.67(2 \mathrm{H}, \mathrm{m}), 1.55$ $(1 \mathrm{H}, \mathrm{m}), 1.35(2 \mathrm{H}, \mathrm{m}), 0.72(6 \mathrm{H}, \mathrm{t}, \mathrm{J}=5.0 \mathrm{~Hz}) \cdot{ }^{13} \mathrm{C}-\mathrm{NMR}(\mathrm{d} \mathrm{ppm}) 139.07(\mathrm{~s})$, 129.62 (d), 128.0 (d), 127.46 (d), 53.81 (d), 46.61 (d), 36.50 (t), $23.71(\mathrm{t})$, $12.47(\mathrm{q})$.

\section{1,1-bis(benzylsulfinyl)-2-ethylbutane (2)}

To a solution of $33.0 \mathrm{~g}$ of (1) $(0.1 \mathrm{~mol})$ in glacial acetic acid $80 \mathrm{~mL}$, a solution of $30.77 \mathrm{~g}(0.2 \mathrm{~mol})$ of trihydrated sodium perborate in glacial acetic acid $(80 \mathrm{~mL})$ was slowly added. The reaction mixture was kept at $42^{\circ} \mathrm{C}$ for $3 \mathrm{~h}$., and monitored by TLC until evidence of the formation of trioxidated products was observed. The mixture was poured on ice and slowly neutralized with 1.0 $\mathrm{M} \mathrm{NaOH}$ solution. The mixture was extracted three times with $\mathrm{CH}_{2} \mathrm{Cl}_{2}(25$ $\mathrm{mL}$ ) and dried with anhydrous sodium sulfate rendering a residue containing disulfoxides (2) and (3). A previous column chromatography purification of the residue (silica gel $60 \mathrm{G}$, particle size $0.2-0.5 \mathrm{~mm}$.) with a mixture of ethyl acetate/n-hexane of increasing polarity, gave, after concentration, a mixture of oxidation products, $88 \%$ yield. Pure meso (2) and racemic (3) was obtained after medium pressure column chromatography (silica gel 60G, particle size 0.02-0.006) with $40 \%$ ethyl acetate in $n$-hexane.

\section{Meso 1,1-bis(benzylsulfinyl)-2-ethylbutane (2)}

Solid, m.p. $108-109^{\circ} \mathrm{C} .{ }^{1} \mathrm{H}-\mathrm{NMR}$ (d ppm) 7.24-7.10 (10H, m), $4.72(1 \mathrm{H}$, $\mathrm{d}, \mathrm{J}=12.9 \mathrm{~Hz}), 3.96(1 \mathrm{H}, \mathrm{d}, \mathrm{J}=12.9), 3.47(1 \mathrm{H}, \mathrm{d}, \mathrm{J}=2.7 \mathrm{~Hz}), 1.71(1 \mathrm{H}, \mathrm{m})$, $1.47(4 \mathrm{H}, \mathrm{m}), 0.53(6 \mathrm{H}, \mathrm{t}, \mathrm{J}=7.4 \mathrm{~Hz}) .{ }^{13} \mathrm{C}-\mathrm{NMR}(\mathrm{d} \mathrm{ppm}) 130.39(\mathrm{~s}), 129.07$ (d), 127.97 (d), $71.99(\mathrm{~d}), 55.30(\mathrm{t}), 40.63$ (d), 40.06 (t), 11.07 (q).

\section{Racemic 1,1-bis(benzylsulfinyl)-2-ethylbutane (3)}

Solid, m.p. $112-113^{\circ} \mathrm{C} .{ }^{1} \mathrm{H}-\mathrm{NMR}(\mathrm{d}$ ppm) $7.33(5 \mathrm{H}, \mathrm{m}), 4.23(1 \mathrm{H}, \mathrm{d}$, $\mathrm{J}=12.87 \mathrm{~Hz}), 3.96(1 \mathrm{H}, \mathrm{d}, \mathrm{J}=12.86 \mathrm{~Hz}), 3.83(1 \mathrm{H}, \mathrm{d}, \mathrm{J}=2.21 \mathrm{~Hz}), 1.93(2 \mathrm{H}, \mathrm{m})$, $1.56(\mathrm{~m}), 1.29(1 \mathrm{H}, \mathrm{m}), 0.89(3 \mathrm{H}, \mathrm{t}, \mathrm{J}=7.17 \mathrm{~Hz}), 0.70(3 \mathrm{H}, 7.39 \mathrm{~Hz}) .{ }^{13} \mathrm{C}-\mathrm{NMR}$ (d ppm) 130.79 (s), 130.52 (d), 130.45 (d), 129.11 (s), 128.99 (d), 128.83 (d), $128.69(\mathrm{~d}), 128.48(\mathrm{~d}), 73.81(\mathrm{~d}), 58.72(\mathrm{t}), 39.56(\mathrm{~d}), 24.59(\mathrm{t}), 23.04(\mathrm{t}), 12.18$ (q), 11.85 (q).

\section{Computing calculations}

The neutral structure was full optimized using B3LYP/6-31+(d',p') level of theory. A vibrational frequency calculation is used to determine whether the structure is a minimum or saddle point on the potential energy surface and to compute the zero-point energy, ZPE. The computations were carried out with the Gaussian 09 suite of programs. ${ }^{6}$

\section{RESULTS AND DISCUSSION}

The synthesis of disulfoxides 1,1-bis(benzylsulfinyl)-2-ethylbutane (2 and 3) was achieved by controlled oxidation of dithioacetal (1), with sodium perborate in glacial acetic acid, producing a 1:1 mixture of meso (2) and racemic (3) modifications, quantified by ${ }^{1} \mathrm{H}-\mathrm{NMR}$. This synthesis is summarized in Scheme 1:

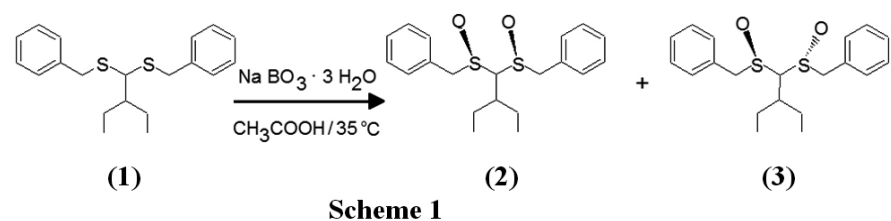

Both compounds were isolated and purified by column chromatography. The expected goal of this work was to incorporate a branched hydrocarbon chain in the a-carbon of the b-disulfoxide to reduce the coordination sphere of the pro-ligand to increase the coordination selectivity for small radius metal ions. See Figure 1. Previously we have reported ${ }^{1} \mathrm{H}-\mathrm{NMR}$ studies to demonstrate that in 1,1-bis(phenylsulfinyl)-methane both sulfinyl oxygens and the phenyl groups are located in an anti orientation. ${ }^{5 b}$ This disulfoxide does not present a significant steric congestion around the methylene bridge, and it was expected both mutual coplanarity as well as facile coordination towards metal ions. X-rays studies by other authors, ${ }^{7}$ have proven this assertion.

In the case of meso 1,1-bis(benzylsulfinyl)-2-ethylbutane an anti orientation for both sulfinyl oxygens and benzyl groups it is to be expected for the free pro-ligand in solution. However, oxygen coordination to a metal ion makes both coplanar benzyl groups closer together, introducing an important steric strain. This steric factor makes coordination less likely. The most probable conformation of meso-1,1-bis (benzylsulfinyl)-2-ethylbutane is indicated in Figure 2. Table 1 shows some selected distances and angles 


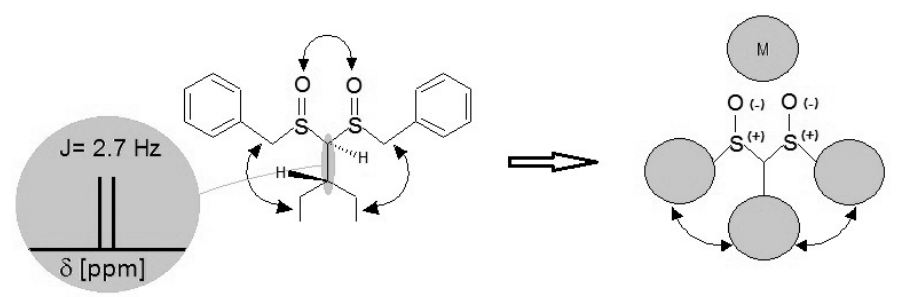

Fig. 1.-Disulfoxide model of high steric compression.

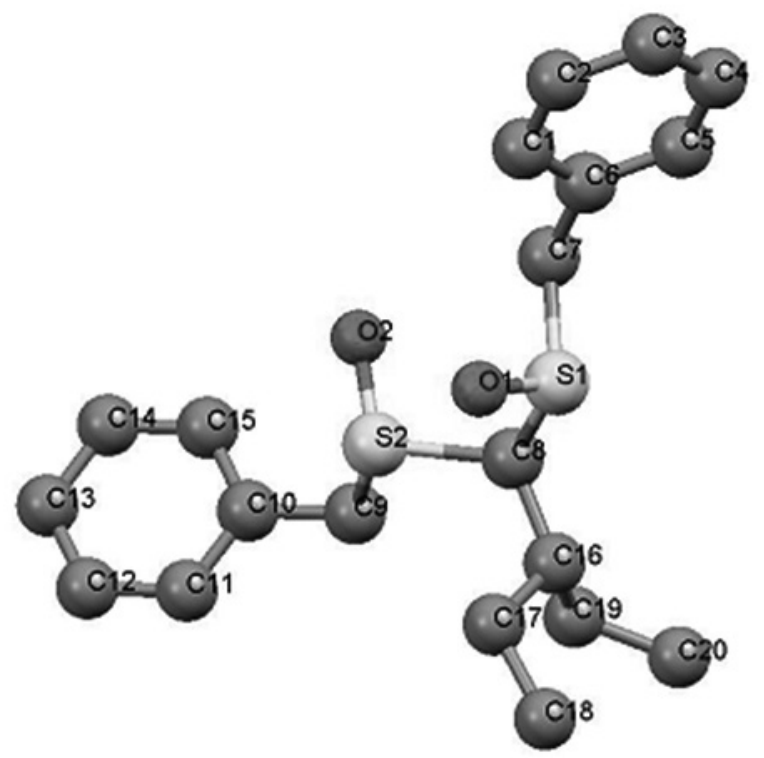

Fig. 2. Proposed structure for Meso-1,1-bis(benzylsulfinil)-2-ethylbutane

Table 1: selected distances and angles.

\begin{tabular}{|c|c|c|c|}
\hline Distance & $\AA$ & Angle & $\circ$ \\
\hline S1-O1 & 1.519 & S1-C8-S2 & 107.65 \\
\hline S2-O2 & 1.522 & C7-S1-C8 & 99.94 \\
\hline S1-C8 & 1.898 & C9-S2-C8 & 98.33 \\
\hline S2-C8 & 1.886 & O1-S1-S2-O2 & 97.59 \\
\hline S1-C7 & 1.875 & C17-C18-C19-C20 & 32.46 \\
\hline S2-C9 & 1.879 & O1-S1-S2-O2 & 97.59 \\
\hline & & C17-C18-C19-C20 & 32.46 \\
\hline
\end{tabular}

A ${ }^{1} \mathrm{H}-\mathrm{NMR}$ analysis of 1,1-bis(benzylsulfinyl)-2-ethylbutane clearly distinguishes meso from the racemic pair. Figure 3, shows the ${ }^{1} \mathrm{H}-\mathrm{NMR}$ spectrum for the mixture of diastereomers, $d l$ and meso compounds (a) and that of meso compound (b)

Two $\mathrm{AB}$ quartets centered at 4.72 and at 3.96 (ppm) with, $\mathrm{J}=12.93 \mathrm{~Hz}$ for the meso and 4.23 and at $3.83(\mathrm{ppm})$ with $\mathrm{J}=12.87 \mathrm{~Hz}$ for the $d l$ pair. The coupling constant between hydrogens in carbons $\mathrm{C}_{8}$ and $\mathrm{C}_{16}, \mathrm{~J}_{\mathrm{H} 8 \mathrm{H} 16}=2.7 \mathrm{~Hz}$ is small, indicating a dihedral angle smaller or more than $90^{\circ}$ between $\mathrm{H}_{8}$ and $\mathrm{H}_{16}$. Methyl groups have been shifted to high field, appearing at $0.53 \mathrm{ppm}$ in the meso compound and 0.70 and $0.89(\mathrm{ppm})$ respectively in the racemic form. These values suggest a fairly perpendicular orientation of both phenyl groups with respect to the alkyl chain. However, the high steric hindrance introduced by both coplanar benzyl results in a closer proximity of both oxygens promoting rotation to minimize steric hindrance. In this conformation, shown as structure Figure 2, ethyl groups should appear at high field and hydrogens in $\mathrm{C}_{8}$ and $\mathrm{C}_{16}$ should be synperiplanar with a small value for $\mathrm{J}_{\mathrm{H} 8 \mathrm{H} 16}$. This analysis is consistent with ${ }^{1} \mathrm{H}-\mathrm{NMR}$ data.

In conclusion methyl and methylene groups have been shifted to high field; 0.53 (ppm) for "meso methyl" and 0.89 and $0.70(\mathrm{ppm})$ for "racemic methyl groups" due to the proximity of aromatic's rings anisotropy. An 'H-NMR analysis of $\mathrm{J}_{\mathrm{H} 8 \mathrm{H} 16}$ for meso and racemic compounds indicates small values for both constants ( 2.7 and $2.1 \mathrm{~Hz}$, respectively). ${ }^{13} \mathrm{C}-\mathrm{NMR}$ data, on the other hand, confirm the shielding experienced by methyl and methylene groups due to the proximity of both benzyl groups, shifting their resonances to 40.6 and $11.0 \mathrm{ppm}$ respectively in meso and $24.6 ; 24.0$ and $12.2 ; 11.8 \mathrm{ppm}$ respectively in the racemic pair. This shielding effect has not been observed in other b-disulfoxides studied so far. ${ }^{5}$
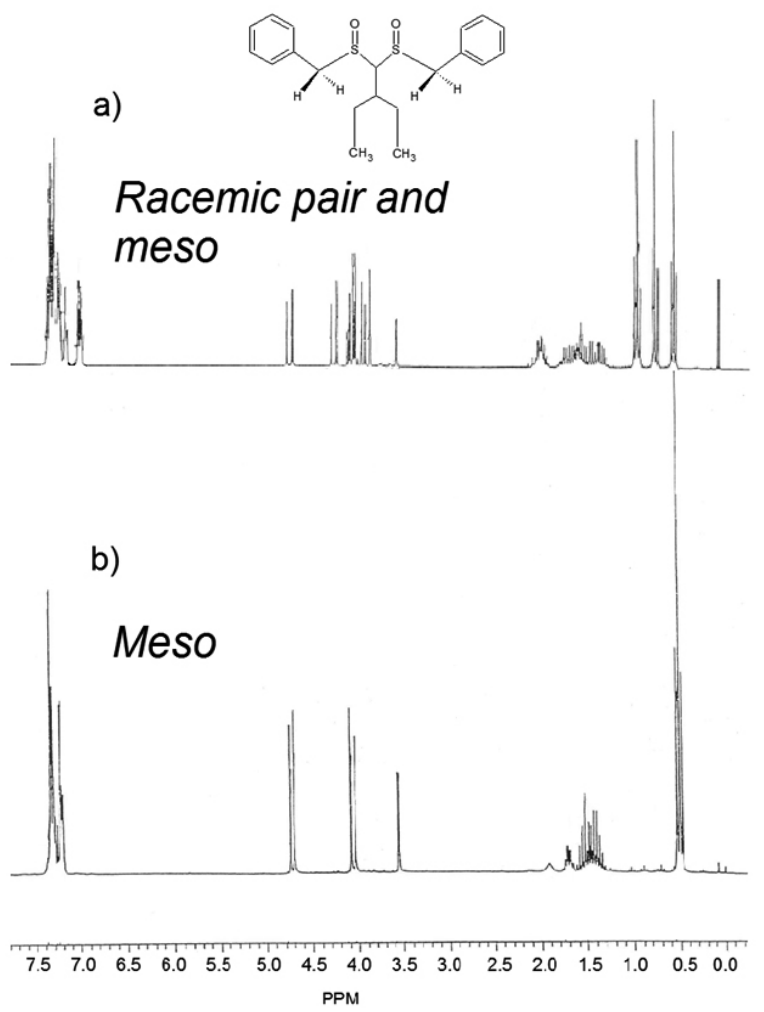

Fig. 3. ${ }^{1} \mathrm{H}-\mathrm{NMR}$ (a) racemic pair and meso 1,1-bis(benzylsulfinyl)-2ethylbutane (b) meso 1,1-bis(benzylsulfinyl)-2-ethylbutane.

A conformation such as structure meso 1,1-bis(benzylsulfinyl)-2ethylbutane in solution should not form metal complexes due to the steric requirements imposed by coplanar benzyl groups. This hinders bonding through oxygens of this disulfoxide; however, we have observed that the racemic modification of compound (3) gives a precipitate with copper (II) ions in solution, reaction not observed for the meso-proligand. Meso-disulfoxide pro-ligands, different to disulfoxides with methylene bridges from 2 up to 4 carbons have successfully produced bridged and chelated complexes with different metal ions. ${ }^{7}$ It is expected that $\mathrm{b}$-disulfoxide pro-ligands behave chemically as b-diketones and b-difosfonates. Studies to dilucidate both the crystal stucture of the copper complex by X-rays and the formation of a complex with the racemic pair are in progress in our laboratory.

\section{CONCLUSION}

It has carried out the synthesis of a new disulfoxide compound with a branched aliphatic carbon chain introduced into the alpha carbon. It has obtained and resolved the Meso and Racemic forms of the disulfoxide 1,1-bis(benzylsulfinyl)-2-ethylbutane. The $\mathrm{H}^{1} \mathrm{NMR}$ analysis has clearly differentiate these forms and theoretical calculus are in agreement with the experimental data

\section{ACKNOWLEDGMENT}

We appreciate the financial support received by University of Concepción, DIUC project $N^{\circ} 210.023 .047 .1$ 


\section{REFERENCES}

1. a) Corey, E. J.; Chaykovsky, M. J. Amer. Chem. Soc. 1964, 86, 1345 b) Madan, S. K.; Hull, C. M.; Herman, L. J. J. Chem. Soc. 1968, 491-495. c) Zipp, A. P.; Madan, S. K. Inorg. Chim. Acta. 1977, 22, 49-53.

2. a) Li, Jian-Rong.; Zhang, Ruo-Hua.; Bu, Xian-He. Aust. J. Chem. 2006, 59, 315-319. b) Chen, Wei.; Du, Miao.; Zhang, Ruo-Hua.; Bu, Xian-He. Chinese J. Struct. Chem. 2002, 5, 277-279. c) Geremia, S.; Calligaris, M.; Mestromi, S. Inorg. Chim. Acta. 1999, 292, 144-146.

3. Kagan, H. B.; Ronan, B. Reviews on Heteroatom Chemistry. 1992, 7, $92-$ 117.

4. a) Gelle'rt Sipos, Emma E. Drinkel, Reto Dorta Chem. Soc. Rev., 2015, 44, 3834 b) Fernández, I.; Araújo, C. S.; Alcudia, F.; Khiar, N. Phosphorous, Sulfur and Silicon, 2005, 180, 1509-1510

5. a) Franco, O. C.; Zárraga, O. M.; Zunza, E. H. Bol. Soc. Chil. Quim. 1995, 40, 319-324. b) Zárraga, O. M.; Zunza, E. H.; Franco, O. C.; Pérez, H. C.; Bol. Soc. Chil. Quim. 1996, 41, 307-309.
6. Gaussian 09, Revision A.01, M. J. Frisch, G. W. Trucks, H. B. Schlegel, G. E. Scuseria, M. A. Robb, J. R. Cheeseman, G. Scalmani, V. Barone, B. Mennucci, G. A. Petersson, H. Nakatsuji, M. Caricato, X. Li, H. P. Hratchian, A. F. Izmaylov, J. Bloino, G. Zheng, J. L. Sonnenberg, M. Hada, M. Ehara, K. Toyota, R. Fukuda, J. Hasegawa, M. Ishida, T. Nakajima, Y. Honda, O. Kitao, H. Nakai, T. Vreven, J. A. Montgomery, Jr., J. E. Peralta, F. Ogliaro, M. Bearpark, J. J. Heyd, E. Brothers, K. N. Kudin, V. N. Staroverov, R. Kobayashi, J. Normand, K. Raghavachari, A. Rendell, J. C. Burant, S. S. Iyengar, J. Tomasi, M. Cossi, N. Rega, J. M. Millam, M. Klene, J. E. Knox, J. B. Cross, V. Bakken, C. Adamo, J. Jaramillo, R. Gomperts, R. E. Stratmann, O. Yazyev, A. J. Austin, R. Cammi, C. Pomelli, J. W. Ochterski, R. L. Martin, K. Morokuma, V. G. Zakrzewski, G. A. Voth, P. Salvador, J. J. Dannenberg, S. Dapprich, A. D. Daniels, Ö. Farkas, J. B. Foresman, J. V. Ortiz, J. Cioslowski, and D. J. Fox, Gaussian, Inc., Wallingford CT, 2009

7. Calligaris, M.; Melchior, A.; Geremia, S. Inorg. Chim. Acta. 2001, 323, $89-95$ 